\title{
Effect of B+ Flux on the electrical activation of ultra-shallow B+ implants in Ge
}

Yates, B.R.; Darby, B.L.; Petersen, Dirch Hjorth; Hansen, Ole; Lin, R.; Nielsen, P.F.; Doyle, B.L.; Kontos, A.; Jones, K.S.

\section{Published in:}

ECS Transactions

Link to article, DOI:

10.1149/05009.0543ecst

Publication date:

2012

Document Version

Publisher's PDF, also known as Version of record

Link back to DTU Orbit

Citation (APA):

Yates, B. R., Darby, B. L., Petersen, D. H., Hansen, O., Lin, R., Nielsen, P.F., Doyle, B. L., Kontos, A., \& Jones, K. S. (2012). Effect of $B^{+}$'Flux on the electrical activation of ultra-shallow $B^{+}$implants in Ge. In ECS

Transactions (pp. 543-549). The Electrochemical Society. https://doi.org/10.1149/05009.0543ecst

\section{General rights}

Copyright and moral rights for the publications made accessible in the public portal are retained by the authors and/or other copyright owners and it is a condition of accessing publications that users recognise and abide by the legal requirements associated with these rights.

- Users may download and print one copy of any publication from the public portal for the purpose of private study or research.

- You may not further distribute the material or use it for any profit-making activity or commercial gain

- You may freely distribute the URL identifying the publication in the public portal 


\title{
Effect of $\mathrm{B}^{+}$Flux on the Electrical Activation of Ultra-Shallow $\mathrm{B}^{+}$Implants in Ge
}

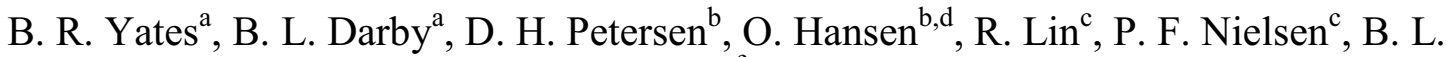 \\ Doyle $^{\mathrm{e}}$, A. Kontos ${ }^{\mathrm{f}}$, and K. S. Jones ${ }^{\mathrm{a}}$ \\ ${ }^{a}$ Department of Materials Science and Engineering, University of Florida \\ Gainesville, Florida 32611, USA \\ ${ }^{\mathrm{b}}$ DTU Nanotech, Department of Micro- and Nanotechnology, Technical University of \\ Denmark, DK-2800 Kgs. Lyngby, Denmark \\ ${ }^{c}$ CAPRES A/S, Scion-DTU, DK-2800 Kgs. Lyngby, Denmark \\ ${ }^{\mathrm{d}}$ CINF, Center for Individual Nanoparticle Functionality, Technical University of \\ Denmark, DK-2800 Kongens Lyngby, Denmark \\ e Sandia National Laboratories, MS-1056, Albuquerque, NM 87185, United States \\ ${ }^{\mathrm{f}}$ Applied Materials, Gloucester, MA 01930
}

The residual implanted dose of ultra-shallow $\mathrm{B}^{+}$implants in $\mathrm{Ge}$ was characterized using elastic recoil detection and was determined to correlate well with simulations with a dose loss of $23 \%$ due to ion backscattering for $2 \mathrm{keV}$ implants in Ge. The electrical characterization of ultra-shallow $\mathrm{B}^{+}$implants at $2 \mathrm{keV}$ to a dose of $5.0 \times 10^{14} \mathrm{~cm}^{-2}$ at beam currents ranging from 0.4 to 6.4 $\mathrm{mA}$ has been studied using micro Hall effect measurements after annealing at $400^{\circ} \mathrm{C}$ for $60 \mathrm{~s}$. It has been shown that the sheet number increases with beam current across the investigated range with electrical activation being $76 \%$ higher at $6.4 \mathrm{~mA}$ as compared to $0.4 \mathrm{~mA}$. However, at $6.4 \mathrm{~mA}$, the electrically active fraction remained low at $11.4 \%$. Structural characterization revealed that the implanted region remained crystalline and amorphization is not able to explain the increased activation. The results suggest the presence of a stable B:Ge cluster whose formation is altered by point defect recombination during high flux implantation which results in increased $\mathrm{B}$ activation.

\section{Introduction}

In recent years, the integrated circuit industry has ventured away from the traditional $\mathrm{SiO}_{2} /$ poly-Si gate structure due to physical scaling restraints and has begun using high$\kappa /$ metal gate structures which has opened the door to new material choices. Germanium has received a renewed interest as a replacement material for silicon in next-generation metal-oxide semiconductor (MOS) devices due to its increased electron and hole mobility as well as reduced contact resistance. With the renewed interest in $\mathrm{Ge}$, there have been a number of recent reports of electrical activation studies of $B^{+}$implants in Ge (1-7). In addition, there were a few experiments completed several decades ago (8-10). However, 
there is a lack of knowledge regarding ion-implanted dopant incorporation, notably on ultra-shallow $\mathrm{B}^{+}$implants. To date, there have been only a few reports regarding the activation behavior of ultra-shallow $\mathrm{B}^{+}$implants in $\mathrm{Ge}$ (11-14).

For ultra-shallow $\mathrm{B}^{+}$implants in Ge, there has been evidence of a B:Ge clustering behavior leading to large fractions of implanted B dose being electrically inactive (13) The behavior is peculiar in that it is independent of implanted dose and occurs in both crystalline (c-Ge) and preamorphized $\mathrm{Ge}$ with the clustering behavior far more pronounced in c-Ge samples. Incomplete activation and B:Ge cluster formation following deep ( $\geq 35 \mathrm{keV}$ ) $\mathrm{B}^{+}$implants into crystalline $\mathrm{Ge}$ is observed, but the inactive fraction appears to be much more significant with shallow implants $(5,6,15)$.

To understand the clustering behavior for ultra-shallow implants in Ge, it is necessary to know the residual chemical dose for a given implant energy. However, the surface proximity increases the difficulty in accurately characterizing the implanted dose using traditional techniques. Elastic recoil detection (ERD) is a viable means for characterizing the implanted dose due to its good depth resolution, its sensitivity to light elements and its ability to measure absolute values without the need for a reference standard.

In an attempt to understand the dopant-defect interactions during implantation and the mechanism behind cluster formation, the effects of varying beam current on the clustering and electrical activation behavior of ultra-shallow $\mathrm{B}^{+}$implants in $\mathrm{Ge}$ is investigated.

\section{Experimental Methods}

Experiments were performed on Czochralski-grown n-type Ge (001) wafers with resistivity greater than $50 \Omega-\mathrm{cm}$. A set of variable beam current samples were diced and $\mathrm{B}^{+}$-implanted at $2 \mathrm{keV}$ to a dose of $5.0 \times 10^{14} \mathrm{~cm}^{-2}$ with beam current varying from 0.4 to $6.4 \mathrm{~mA}$. The beam size is estimated to be $180 \mathrm{~cm}^{2}$ which yields an ion flux range of $1.38 \times 10^{13}$ to $2.21 \times 10^{14}$ ions $/\left(\mathrm{s}-\mathrm{cm}^{2}\right)$ for $0.4 \mathrm{~mA}$ and $6.4 \mathrm{~mA}$, respectively. During $\mathrm{B}^{+}$ implantation, the platen was held at $25^{\circ} \mathrm{C}$. Samples were processed in a Heatpulse 4100 rapid thermal annealer (RTA) in $\mathrm{N}_{2}$ ambient at $400^{\circ} \mathrm{C}$ for $60 \mathrm{~s}$ to activate the implanted $\mathrm{B}$. High-resolution cross-sectional transmission electron microscopy (HR-XTEM) was completed using a JEOL 2010F to image the microstructure of specimens before and after annealing. TEM samples were prepared using a FEI DB235 focused ion beam.

Electrical characterization was completed using a CAPRES microRSP M-150 M4PP with Au-coated probes, a probe spacing of $20 \mu \mathrm{m}$, and a permanent magnet with a magnetic flux density of $0.475 \mathrm{~T}$. Hall sheet number $\left(n_{H}\right)$ and mobility values $\left(\mu_{H}\right)$ were adjusted to obtain the carrier sheet number $\left(n_{s}\right)$ and drift mobility $\left(\mu_{d}\right)$ by using a scattering factor $\left(r_{H}\right)$ of 1.21 as determined empirically by Mirabella et al (1). The carrier density and drift mobility are related to the Hall values by $n_{s}=n_{H} \times r_{H}$ and $\mu_{d}=\mu_{H} / r_{H}$, respectively.

To characterize the as-implanted chemical dose of ultra-shallow $\mathrm{B}^{+}$implants in Ge, a set of variable energy samples were implanted at 2, 4, and $6 \mathrm{keV}$ to a dose of $5.0 \times 10^{15}$ $\mathrm{cm}^{-2}$ and characterized using elastic recoil detection (ERD). A dose of $5.0 \times 10^{15} \mathrm{~cm}^{-2}$ was used to increase counts and decrease experimentation time. ERD characterization was 
performed using the ${ }^{11} \mathrm{~B}\left({ }^{28} \mathrm{Si},{ }^{11} \mathrm{~B}\right)$ reaction with a $28 \mathrm{MeV} \mathrm{Si}^{4+}$ beam with the Ge target tilted at $75^{\circ}$ from incidence and a recoil angle of $30^{\circ}$. A $12 \mu \mathrm{m}$ mylar foil was used to shield forward scattered Si ions and to allow the recoiled B atoms to enter the detector. The areal density of implanted boron was calculated using a spectral scaling approach (16).

\section{Results \& Discussion}

To confirm the residual implanted dose of ultra-shallow $\mathrm{B}^{+}$implants in Ge, samples implanted to a dose of $5.0 \times 10^{15} \mathrm{~cm}^{-2}$ were characterized using ERD. The residual implanted dose for samples implanted at 2,4 , and $6 \mathrm{keV}$ was found to be $3.84 \times 10^{15} \mathrm{~cm}^{-2}$, $3.88 \times 10^{15} \mathrm{~cm}^{-2}$, and $4.12 \times 10^{15} \mathrm{~cm}^{-2}$, respectively. The deviation from the implanted dose is significant as it is in excess of $20 \%$ of the implanted dose for the lowest implant energy. As speculated in previous works, it is believed that ion backscatter is a large source of dose loss and at first inspection could seemingly enhance the inactivation of the $\mathrm{B}^{+}$ implant (13). Due to the low atomic mass of B in comparison to Ge, it is highly susceptible to ion backscattering during implantation which reduces the chemical dose before any other processing is completed. Taking into account that samples were characterized as-implanted, it is assumed that the deviation from implanted dose is due completely to backscattering losses during implantation. Boron is known to diffuse very slowly in Ge and no further dose loss is expected following annealing at $400^{\circ} \mathrm{C}$ for $60 \mathrm{~s}$ $(17,18)$.

Fig. 1 shows the percentage of implanted $\mathrm{B}^{+}$lost to backscattering as a function of implant energy as measured with ERD is plotted in conjunction with TRIM simulations (19). The simulations compare favorably with the dose loss values experimentally determined through ERD and confirm that a large portion of the implanted dose is lost to ion backscattering. Given that backscattering is an energy-dependent phenomenon, it is assumed that this behavior is identical for lower doses. The experiment confirms that TRIM simulations are sufficient for estimating the retained implanted dose for ultrashallow $\mathrm{B}^{+}$implants in Ge.

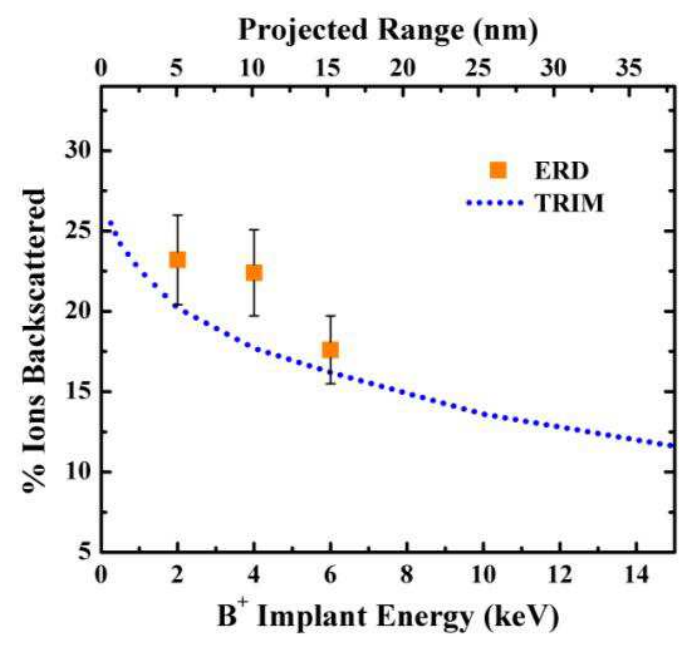

Figure 1. Percent of B ions backscattered as a function of implant energy into Ge as simulated by TRIM and experimentally determined through ERD for a $5.0 \times 10^{15} \mathrm{~cm}^{-2}$ implant into Ge. 
In Fig 2, the sheet resistance, $R_{s}$, is plotted as a function of beam current for $2 \mathrm{keV} \mathrm{B}{ }^{+}$ implants to a dose of $5.0 \times 10^{14} \mathrm{~cm}^{-2}$ after annealing $400^{\circ} \mathrm{C}$ for $60 \mathrm{~s}$. A trend of decreasing $R_{s}$ with increasing beam current is observed across the investigated range. At $6.4 \mathrm{~mA}$, the measured $R_{s}$ value is $675.2 \Omega / \mathrm{sq}$ as compared to $931.5 \Omega / \mathrm{sq}$ at $0.4 \mathrm{~mA}$. Interestingly, the decrease in $R_{S}$ can be explained by an increase in activation as seen in Fig. 3a. At $6.4 \mathrm{~mA}$, the $n_{s}$ was $4.55 \times 10^{13} \mathrm{~cm}^{-2}$ which is an increase of $76 \%$ from the lowest current. In Fig. $3 \mathrm{~b}$, the drift mobility as a function of beam current is shown. Due to the increase in ionized dopants, the drift mobility decreases with current to a minimum of $203.2 \mathrm{~cm}^{2} / \mathrm{V}-\mathrm{s}$ which is expected in this doping regime (1).

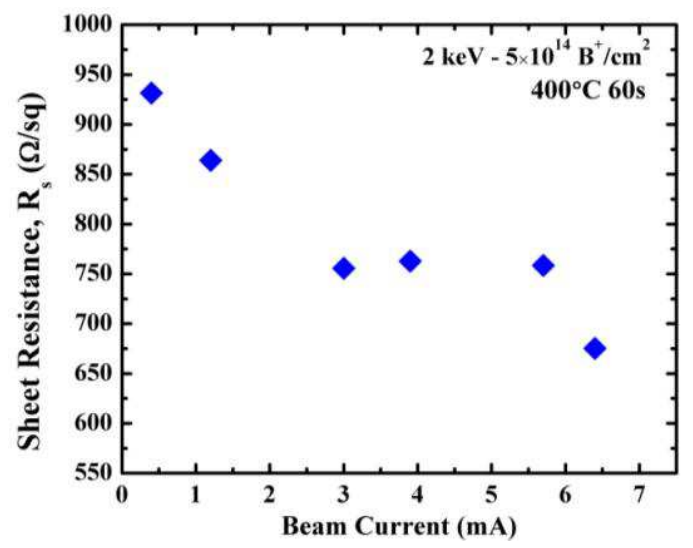

Figure 2. Measured sheet resistance $\left(R_{S}\right)$ after annealing at $400{ }^{\circ} \mathrm{C}$ for $60 \mathrm{~s}$ as a function of beam current implanted at $2 \mathrm{keV}$ to a dose of $5.0 \times 10^{14} \mathrm{~cm}^{-2}$ into crystalline Ge.
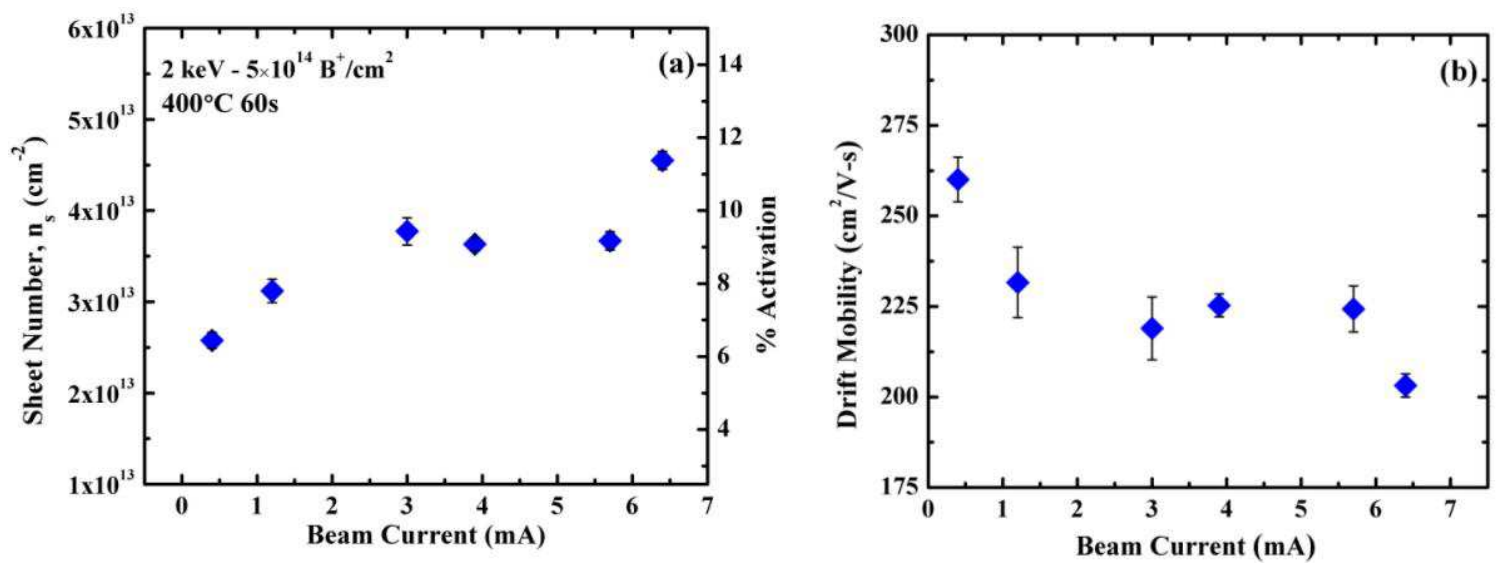

Figure 3. (a) Measured sheet number $\left(n_{s}\right)$ and percent electrical activation and (b) drift mobility $\left(\mu_{D}\right)$ as a function of beam current implanted at $2 \mathrm{keV}$ to a dose of $5.0 \times 10^{14} \mathrm{~cm}^{-2}$ into crystalline Ge after annealing at $400{ }^{\circ} \mathrm{C}$ for $60 \mathrm{~s}$.

The microstructure of the samples was characterized using HR-XTEM both asimplanted and post anneal. Fig. 4 shows an image of the $6.4 \mathrm{~mA}$ sample in the asimplanted case. The samples implanted at 0.4 and $6.4 \mathrm{~mA}$ both appeared unremarkable with no discernible difference between the samples as-implanted and post anneal. The presence of any amorphization was not observed in the as-implanted case and extended defects were not observed in the annealed case for any sample. The lack of 
amorphization of the $6.4 \mathrm{~mA}$ sample gives credence to the notion that the increased beam current altered the point defect environment during implant which led to the reduction of clustering.

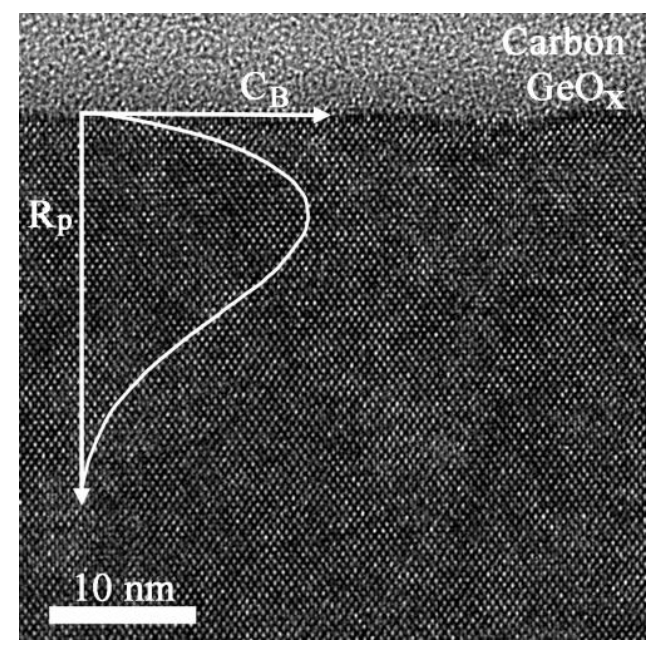

Figure 4. HR-XTEM micrograph of an as-implanted crystalline Ge sample $\mathrm{B}^{+}$implanted at $2 \mathrm{keV}$ to $5.0 \times 10^{14} \mathrm{~cm}^{-2}$ at a beam current of $6.4 \mathrm{~mA}$ showing a $2.9 \pm 0.3 \mathrm{~nm}$ surface $\mathrm{GeO}_{\mathrm{x}}$ layer and no evident implant damage or amorphization present near the projected range, $R_{p}$. A simulation of the $\mathrm{B}$ profile is overlaid on the image.

Despite the increase in carriers with increasing beam current, the overall activation of the samples is far from complete activated with the highest value achieved at $11.4 \%$; where the active fraction is simply the sheet number divided by the residual dose as simulated by TRIM. This finding is not surprising given the recent report of an anomalous clustering behavior in Ge which had reported $\sim 10 \%$ activation for $2 \mathrm{keV} \mathrm{B}$ implanted at doses ranging from $5.0 \times 10^{13} \mathrm{~cm}^{-2}$ to $5.0 \times 10^{15} \mathrm{~cm}^{-2}$ (13). Previous reports have reported incomplete activation for higher energy implants in Ge and have attributed it to B:Ge cluster formation $(5,6,15)$.

It should be noted that the observed increase in active carriers is not believed to be due to any beam heating effects due to the platen being held at room temperature during the implantation. For Si, it is well-known that varying the beam current during implantation can significantly alter the resulting microstructure through ion beam induced recrystallization or amorphization $(20,21)$. At elevated temperatures, a subtle change in the ion flux is capable of influencing the point defect environment surrounding the crystalline-amorphous interface in such a way that it may recrystallize or further amorphize the layer depending on an increase or decrease in beam current, respectively. Several studies regarding ion beam induced recrystallization and amorphization have been completed with Ge which have reported similar findings (22-24). Notably, Sigurd et al. have reported that for $\mathrm{B}$ ions in $\mathrm{Ge}$, the lattice disorder produced is ten times higher than what is observed in Si at room temperature (22). These results are likely explained through the lower amorphization threshold of Ge as compared to $\mathrm{Si}$ (25). However, for light ions such as B, the amorphous layer is not as thick nor is amorphization observed at the projected range of the ion as predicted by simulations for heavier ions, but rather occurs closer to the surface (26). The dilute damage cascades created by light ions allow Frenkel pairs created during implantation to recombine or to form larger, stable 
complexes such as a B:Ge cluster. Therefore, by increasing the beam current during implantation, the point defect environment is altered which allows for a reduction in the formation of B:Ge clusters.

\section{Conclusions}

The residual implanted dose for ultra-shallow $\mathrm{B}^{+}$implants in $\mathrm{Ge}$ was characterized using ERD and compare favorably with simulations suggesting a dose loss due to backscattering of $23 \%$. Samples implanted at $2 \mathrm{keV}$ to a dose of $5.0 \times 10^{14} \mathrm{~cm}^{-2}$ at varying ion beam current were characterized using micro four point probe and micro Hall effect techniques. The results show a decrease in $R_{s}$ with increasing beam current due to an increase in electrical activation. However, despite the increase in activation, the highest sheet number obtained was $4.55 \times 10^{13} \mathrm{~cm}^{-2}$ which corresponds to a maximum active fraction of $11.4 \%$. HR-XTEM characterization showed no discernible microstructural difference between samples. The results suggest a B:Ge cluster formation that is altered through a change in the point defect environment with increased beam current during implantation.

\section{Acknowledgments}

The authors acknowledge the Intel Corporation for funding this work and the Major Analytical Instrumentation Facility at the University of Florida for the use of the FIB and TEM facilities. CINF is sponsored by The Danish National Research Foundation. Sandia is a multiprogram laboratory operated by Sandia Corporation, a Lockheed Martin Company, for the United States Department of Energy under contract DE-AC0494AL85000.

\section{References}

1. S. Mirabella, G. Impellizzeri, A.M. Piro, E. Bruno, and M.G. Grimaldi, Appl. Phys. Lett., 92, 251909 (2008).

2. Y.-L. Chao, S. Prussin, J.C.S. Woo, and R. Scholz, Appl. Phys. Lett., 87, 142102 (2005).

3. Yu-Lin Chao and J.C.S. Woo, Electron Devices, IEEE Transactions 54, 27502755 (2007).

4. Y.S. Suh, M.S. Carroll, R.A. Levy, M.A. Sahiner, G. Bisognin, and C.A. King, IEEE Transactions On, 52, 91- 98 (2005).

5. Yong Seok Suh, M.S. Carroll, R.A. Levy, G. Bisognin, D. De Salvador, M.A. Sahiner, and C.A. King, IEEE Transactions On 52, 2416-2421 (2005).

6. G. Impellizzeri, S. Mirabella, E. Bruno, A.M. Piro, and M.G. Grimaldi, J. Appl. Phys,. 105, 063533 (2009).

7. F. Panciera, P.F. Fazzini, M. Collet, J. Boucher, E. Bedel, and F. Cristiano, Appl. Phys. Lett., 97, 012105 (2010).

8. $\quad$ K.S. Jones and E.E. Haller, J. of Appl. Phys., 61, 7 (1987).

9. V.M. Gusev, M.I. Guseva, E.S. Ionova, A.N. Mansurova, and C.V. Starinin, Phys. Stat. Sol,. 21, 413-418 (1974).

10. M.I. Guseva and A.N. Mansurova, Radiation Effects, 20, 207-210 (1973).

11 A. Satta, E. Simoen, T. Clarysse, T. Janssens, A. Benedetti, B. De Jaeger, M. Meuris, and W. Vandervorst, Appl. Phys. Lett., 87, 172109 (2005). 
12. E. Simoen, G. Brouwers, A. Satta, M.-L. David, F. Pailloux, B. Parmentier, T. Clarysse, J. Goossens, W. Vandervorst, and M. Meuris, Mat. Sci. in Semicon. Process., 11, 368-371 (2008).

13. B.R. Yates, B.L. Darby, N.G. Rudawski, K.S. Jones, D.H. Petersen, O. Hansen, R. Lin, P.F. Nielsen, and A. Kontos, Mater. Lett., 65, 3540-3543 (2011).

14. G. Hellings, E. Rosseel, T. Clarysse, D.H. Petersen, O. Hansen, P.F. Nielsen, E. Simoen, G. Eneman, B. De Jaeger, T. Hoffmann, K. De Meyer, and W. Vandervorst, Microelectronic Engineering 88, 347-350 (2011).

15. G. Bisognin, S. Vangelista, M. Berti, G. Impellizzeri, and M.G. Grimaldi, J. Appl. Phys., 107, 103512 (2010).

16. B.L. Doyle and D.K. Brice, Nucl. Instrum. Methods Phys. Res. B, 35, 301-308 (1988).

17. S. Uppal, A.F.W. Willoughby, J.M. Bonar, A.G.R. Evans, N.E.B. Cowern, R. Morris, and M.G. Dowsett, J. Appl. Phys., 90, 4293 (2001).

18. S. Uppal, A.F.W. Willoughby, J.M. Bonar, N.E.B. Cowern, T. Grasby, R.J.H. Morris, and M.G. Dowsett, J. Appl. Phys., 96, 1376-1380 (2004).

19. J.F. Ziegler, Nucl. Instrum. Methods Phys. Res. B, 219-220, 1027-1036 (2004).

20. R.G. Elliman, J.S. Williams, W.L. Brown, A. Leiberich, D.M. Maher, and R.V. Knoell, Nucl. Instrum. Methods Phys. Res. B, 19-20, Part 2, 435-442 (1987).

21. R.G. Elliman, S.T. Johnson, A.P. Pogany, and J.S. Williams, Nucl. Instrum. Methods Phys. Res. B, 7-8, 310-315 (1985).

22. D. Sigurd, G. Fladda, L. Eriksson, and K. Björkqvist, Radiation Effects, 3, 145147 (1970).

23. G. Holmén, S. Peterström, A. Burén, and E. B $\oslash$ gh, Radiation Effects, 24, 45-50 (1975).

24. J. Linnros and G. Holmén, J. of Appl. Phys., 62, 4737-4744 (1987).

25 S. Koffel, P. Scheiblin, A. Claverie, and G. Benassayag, J. of Appl. Phys., 105, 013528 (2009).

26. A. Claverie, S. Koffel, N. Cherkashin, G. Benassayag, and P. Scheiblin, Thin Solid Films, 518, 2307-2313 (2010). 